March 19th.-Induration of the tubercles less defined, and the glands under the jaw smaller. He looked paler, and felt weaker than before-probably from the combined effects of scanty diet with mercurialization, as he had been ont of work that week. I ordered him to take a little quinine-and-iron, and to take his pill once a day only.

30th. - The glands under the neck were less enlarged, the coppery tint of the patches on the face much fainter, and the induration withering. The throat still not sore; and no other eruption visible on the body.

April 20th. - The coppery discoloration remained in two places only, and was of very small extent. The induration of the tubercles was perceptible in one cicatrix only. The eye was quite well, except that the lashes had not grown again. The lymphatic glands were of their usual size, and the man felt quite well. Having found work in the country, he had been unable to show himself at the hospital, and had not taken medicine for a fortnight. He was ordered to continue his pill once every other day for a little time longer.

On the 26th of March the patient led in his late antagonist for examination, of whose condition I took the following note:-F. M-, aged thirty-one, a wheelwright, of intem. perate habits. He stated that when he sucked John J-'s eye he had a sore at the corner of his month (where there is one still), and that he had some sores on his penis at that time, which had existed for six weeks or two months before the time at which he gave the blow to John J-; but they did not trouble him much. However, he recollects that the lumps now in his groin were there then, and that they were rather tender. He has never observed any rash on his skin or soreness in his throat, and has felt very well ever since. On examination, the sore proves to be a fissure at the left angle of the mouth, with one or two enlarged papillæ round it, which are moist and scaling, not possessing any induration however. There is no ulceration on the mucous surfaces of the mouth and fauces; the lymphatic glands are not enlarged under the jaw, or at the back of the neck. The body is free from eruption of any kind, save that one or two acne spots on his shoulder have a coppery tint. On the penis, behind the corona glandis, are two scars, with well-marked induration-the sites, the patient says, of the sores he had last December. The lymphatic glands in both groins are plainly enlarged, but not at all tender, and the skin covering them is of its usual colour. He has never taken any medicine for his disease; and the only inconvenience of which he has been conscious is the persistent sore on the mouth. I ordered him a small quantity of bichloride of mercury, with iodide of potassium. This treatment has been pursued during the month of April, and the sore on his mouth has healed. The induration has much diminished on the penis, and the patient has preserved his good health.

These cases show very clearly:- - First. That there exists an incubation period in syphilis between the moment of inoculation and the manifestation of its effects, which has a duration not very exactly known. In the cases of V. Bärensprung, where inoculation was purposely practised, the incubation lasted twenty-eight and twenty-nine days; sigmund and Rollet both estimated it at about three weeks, with extremes of fourteen and forty-two days; Hunter relates an instance of two months intervening between the time of contagion and the appearance of the disease; and Aime Martin, in his thesis for 1862, mentions the case of a girl incarcerated in the St. Lazare Prison, in close confinement on the 15th July, 1861, on whose labium a syphilitic sore made its appearance on the 25 th September following-a period of seclusion of seventy-two days. The case I am relating had a long period of incubation, about five weeks or rather more, as nearly as can be estimated, bu not of an extreme length if compared with those related by other observers. Secondly. The kind of primary lesion pro duced by the disease when other disturbing causes are absent is here well shown. The indurated tubercles grew at the point of inoculation, and never ulcerated, perhaps becanse they were free from irritation, resulting from the moistening by secretions, nrine, \&c.; though I do not mean that such irritation is in all cases the cause of ulceration in primary syphilitic affections, but that these are probable causes of it in many instances. These papules or tubercles-for some resembled one and some the other-had been slowly developing themselves for six or seven weeks, and had become indurated to such an extent that one was as large as a sixpence; yet their surface was unbroken in all that time. In this case at least the primary affection bore no resemblance to a Hunterian chancre. Thirdly. The disease was communicated by contagion with secondary secretions-namely, the fluid exuding from the sore at the angle of the second patient's mouth was inoculated into the open wounds of the cheek of the first patient; and that this sore was a secondary affection is shown by the pre-existence of the primary disease in another part of the man's body, which, since we cannot produce a primary lesion of syphilis on a person already subject to the disease, prevents the possibility of the sore at the month being one.

I have brought forward these cases for the readers of THE LANCET, because they are examples of an unusual mode of communicating the disease-namely, by suction of open wounds, though a precisely similar means of contamination takes place when nurses are inoculated by their foster-children, in which cases the primary lesion is a chancre on the breast.

Weymouth-street, June, 1864.

\section{ON A CASE OF POISONING BY ARSENIC.}

Bx C. W. BINGLEY, Ph.D., F.C.S., LECTURAR ON CHEMISTRX TO THR SHEFFIBLD SOHOOL OP MBDTGINE.

In cases of death from arsenic, what evidence can a post-mo'tem examination and analysis afford, either as to the probable quantity taken, or the period that may have afterwards elapsed before death took place?

THe following are the particulars of a case $I$ have lately been retained in, suggestive of the above inquiry. Charlotte $\mathbf{P}$ of Crowle, in Lincolnshire, a married woman, between thirty. five and forty years of age, died suddenly. At the inquest, the evidence was, that a neighbour saw her in her own house about five o'clock in the afternoon previous to her death, sitting by the fire-side. She appeared to be ailing. The witness asked her what was the matter, but the deceased was unwilling to say much, and only replied "she didn't know." Soon afterwards the witness left her. The next morning, about six o'clock, deceased's husband called her into his house, when she found his wife had died. The husband, a labourer, on being examined, said that he had been out drinking; that when he got home it was late, and he found his wife in bed and ill. $\mathrm{He}$ said he was drank, but he got her some tea, and directly she took it she was sick, and vomited. She vomited twice. ${ }^{*}$ She got out of bed, and was seized with cramp in the legs, and could not get back into bed. She asked him to lift her in; whilst doing so she kissed him, and said it would be the last time he would ever have to do it for her. He went to sleep. About five o'clock, when he woke, he found his wife dead. He had no one to assist him with his wife during the night. No evidence could be obtained of any poison having been bought by, or seen in the possession of, either the deceased or her husband, nor were the remains of any to be found. The only druggist in the town who sold arsenic denied having ever supplied either the deceased or her husband with any. It was stated that deceased and her husband frequently quarreled, and that he was a very intemperate man. The general belief amongst the neighbours, however, was that she had died from natural causes, or if from poison that she bad taken it intentionally. The medical man of the place was of opinion that she had died from natural causes. Mr. Holgate, the coroner, however, adjourned the inquest, and ordered that in the meantime Mr. Moxon, of Kirton Lindsay, surgeon, shonld obtain the viscera of the deceased, and send them to me for analysis.

I accordingly received the stomach, a portion of the small intestines and contents, the gall-bladder, and a portion of the liver of the deceased. The result of my examination and ana. lysis of them was, as stated at the adjonrned inquest, in substance as follows-viz., I found the stomach to contain four fluid ounces of a mucous liquor tinged with blood of a dark colour; blood of a dark colour suffused between the rugr; no ulceration nor perforation of the coating of the stomach; but the whole presented an inflamed condition, and was of a dull reddish-brown colour, that became brighter after exposure to the air. The small intestines were inflamed, especially that part of the duodenum adjoining the pylorus. No specks nor pasty patches of arsenic could be detected either in the stomach or intestines. The gall bladder was full of gall. The liver was uniformly of a brownish-red colour, and presented no appearance of inflammation. On analysis, I discovered arsenic. The distillates with chlorhydric acid from each of the respective portions furnished, by the usual methods, tersulphide of arsenic

* The vomit had been thrown away, and was not to be recoverod when $I$ inquired for it afterwards. 
equivalent to the several quantities of arsenious acid followingviz.: The stomach $0.86 \mathrm{grs}$; ; contents of ditto, $0.02 \mathrm{grs}$. The portion (nearly half) of the small intestines emptied, $1.04 \mathrm{grs}$.; contents of ditto (eight fluid ounces), a trace only. The gallbladder and gall, 1.13 gr. The portion (not quite half) of the liver, $4 \cdot 15$ grs.

From the fact of my finding so small a portion of arsenic either in the stomach or intestines and their contents, compared with so much larger a quantity in the liver, the question suggested itself whether the deceased might not have had the arsenic administered to her, presuming in that case it had been exhibited in a smaller dose than a person with suicidal intent would have taken it, and that it had been given some rather more considerable length of time previous to death, so as to have admitted of its absorption to the extent $I$ found had taken place in the liver.

The cases recorded of arsenical poisoning are exceedingly anomalous as to the effects and symptoms exhibited. I could find none that $I$ could apply in this case; and, in the absence of any other evidence to explain how or when the poison had been obtained and dealt with, could form only a speculative opinion on a point that might implicate a second party.

The verdict therefore was, "That the deceased had died from the effects of arsenic; but whether administered to her by anyone, or that she took it herself, there was no evidence to show."

\section{1) ithrot}

OF THE PRACTICE OF

\section{MEDICINE AND SURGERY \\ IN THR}

\section{HOSPITALS OF LONDON.}

Nulla autem est alia pro certo noscendi via, nisi quamplurimas et morboruem et dissectionum historias, tum aliorum, tum proprias collectas habere, et in se comparare,-Blong LeNI De Sed. et Caus. Morb., lib.iv. Procmium.

\section{ST. THOMAS'S HOSPITAL.}

CASES ILLUSTRATIVE OF INJURTES TO THE ABDOMEN, WITH CLINICAL REMARKS.

(Under the care of Mr. LE Gros Clark.)

CAsE 1.-J. G-_, aged twenty-two, a drayman, was admitted Oct. 8th, 1863. He had been jammed between the shaft of his dray and the wheel of a van, and was dragged along for some distance before he could clear himself. On ex. amination there was no external appearance of injury, but his state of collapse, pain across the stomach, and constant sick. ness suggested the possibility of some serious organic lesion. His urine was drawn off free from blood, and hot bottles were applied to his feet as soon as he was placed in bed. The sickness continued through the night, and the pain across the epigastrium was severe. Bowels relieved; much thirst; pulse 94.

Towards the close of the second day he improved in appearance; his stomach became less irritable, and he passed urine freely.

On the third day he was much improved in every respect, and less pain was complained of. Took light nourishment freely.

Fifth day.-He had more abdominal pain, but this was not increased on pressure. In other respects, with the exception of more thirst, he was much the same.

Sixth day.-More feverish and restless. The abdominal pain was increased, and accompanied by tenderness; pulse 108; face jaundiced and anxious. It was evident that diffused peritonitis was commeneing. The abdomen was constantly fomented, and two grains of blue pill, with half a grain of opium, were given every six hours. The bowels were open.

Eighth day.-Abdominal effusion to a moderate extent; his general symptoms were somewhat improved.

During the succeeding week his condition varied, andithe effusion at one time even diminished in quantity, and the jaundice somewhat abated. Afterwards tympanitis, with increased tenderness, ensued, and he at last sank rapidly, and died on the eighteenth day after the accident.

A utopsy. - The peritoneal cavity contained about five gallons of somewhat turbid fluid, coloured with bile, and the intestines and other viscera were also deeply stained with bile. There was a large quantity of soft lymph effused about the upper surface of the liver, and the serous covering of the intestines was thickened by deposits of lymph. The peritoneum lining the anterior abdominal wall was rough and congested. The abdominal contents were remarkably free from putridity. The liver was large ; it presented a laceration on the lower surface, passing from the anterior margin backwards, close to and parallel with the gall-bladder. In the posterior part of this wound the right hepatic duct was seen to be torn nearly across at its commencement from the common duct, the left branch being uninjured. The gall-bladder and cystic duct were also uninjured; but the latter was much contracted, so as not to admit a probe easily. The spleen was large, and its capsule thickened. There was a quantity of firm, pale coagulum beneath the serous covering of the right kidney. There were no external marks of injury, except a bruise on the right shonlder.

CASE 2.-R. S—_, aged thirty-seven, painter, admitted on Dec. 30th, 1863. He had been struck down and run over by an omnibus, a wheel of which had passed over the lower part of the abdomen in a direction obliquely upwards from the right groin. The course of the wheel was marked by severe contusion. His face was also much cut and bruised. When admitted he was in a state of collapse, pale, and cold; his eyes glassy; his pulse imperceptible. Some ammonia was administered, and a catheter was passed, through which a small quantity of bloody urine was drawn off.

Early on the following morning the elastic catheter was again introduced and kept in. Much bloody urine was withdrawn. There was now constant sickness, and his pulse was very feeble. He spat up a small quantity of blood. Towards evening of this day reaction came on, and with the quickened circulation and hot skin, much abdominal tenderness, especially just above the pubes; urine still bloody. He was taking beef-tea and milk, and an opiate was ordered at night, with brandy if needed; hot fomentations to the abdomen.

On the third day the urine was still high-coloured, but bloodless; pulse improved ; abdominal tenderness, with some tension, continued; has again spat up some blood; bowels relieved.

On the fourth day all his symptoms were improved.

On the fifth he had severe intermittent pain, with sickness, the abdominal tenderness continuing, and the urine being again coloured with blood.

On the seventh day there was increased tension of the abdomen, without diminution of tenderness; pain on pressure; some delirium. On the ninth day the pulse was improved; but the pain continued, with distension, and some fluctuation was perceptible. The patient was ordered an improved diet, (the tongue being clean,) some gin, and the opium to be continued at night. The catheter was changed from time to time, but still kept in. Considerable difficulty was experienced in introducing it. Urine now free from blood. From this date there was gradual improvement, with occasional relapses of pain. The bladder gradually resumed its normal function. The distension, tenderness, and fluctuation slowly and simultaneously subsided; and he ultimately left the hospital on the 9th of February, free from inconvenience in micturition, and with the urine in a healthy condition, though still pale and feeble.

CASE 3.-J. C- - aged thirty, a carpenter, was admitted on the 27th of August, 1863. He slipped, while engaged in unloading a waggon, and half a ton weight of timber fell across his abdomen. He was immediately brought to the hospital in a pulseless state of collapse. Acute pain and tension of the abdomen soon followed; breathing thoracic. A catheter was passed, and clear urine flowed. The patient was placed in warm blankets, with hot bottles to the feet, and, as the collapse was threatening, some brandy and landanum were given. In the evening the respiration was hurried, the pulse rery feeble, and the abdominal suffering increased; countenance anxious; constant vomiting of a dark-brown fluid. Death occurred within twenty-four hours of the accident.

Autopsy. - The peritoneal cavity contained gas, and a considerable quantity of turbid, reddish-coloured, and fetid fluid. The intestines were slightly glued by lymph, with congestion and ecchymosis. There was an extensive rent in the mesentery of the jejunnm, and a double rupture of the intestine itself, about three quarters of an inch of its circumference being torn through in $t$ wo places. There was no other lesion. 